\title{
Os desafios da COVID-19 aos Direitos Humanos
}

\author{
COVID-19's Challenges to Human Rights
}

Desafíos de COVID-19 a los derechos humanos

Maria do Céu Patrão Neves ${ }^{1}$

\section{Resumo}

A pandemia de COVID-19, na tripla crise que desencadeou - sanitária, económica e social -, tem provocado o maior retrocesso na implementação dos Direitos Humanos de que há memória desde a sua Declaração Universal, em 1948. Esta avaliação decorre da amplitude e profundidade do recuo na realização dos direitos humanos que se verifica actualmente em três planos, correspondendo, de uma forma genérica, às três gerações de direitos: no plano individual, contemplando os direitos civis e políticos; no social, os direitos económicos e sociais; e no global, os direitos de titularidade colectiva ou de solidariedade. Deter-nos-emos, sucessivamente, nestes diferentes planos, considerando algumas das mais comuns e impactantes medidas sanitárias implementadas em cada um e que constituem transgressões aos direitos humanos, reflectindo sobre as eventuais condições de legitimação ética das medidas adoptadas. Paralelamente, importa considerar que as medidas sanitárias implementadas não só vêm atingindo o respeito pelos Direitos Humanos, mas têm igualmente originado áreas de conflito entre diferentes direitos, em relação aos quais não é eticamente legítimo optar por uns em detrimento de outros. Defende-se ser necessário avançar para uma nova abordagem dos direitos humanos, destacando a sua complementaridade e sustentabilidade nos deveres - num modelo integrado - o que, por sua vez, deverá contribuir para a articulação de todos os direitos e seu respectivo cumprimento.

\section{Palavras-chave}

Direitos Humanos. Deveres. Liberdade, Igualdade. Fraternidade.

\begin{abstract}
The COVID-19 pandemic, in the triple crisis it triggered - health, economic and social - has caused the greatest setback in the implementation of Human Rights since its Universal Declaration, in 1948. This assessment stems from its amplitude and the depth of the reversion in the realization of human rights that is currently verified on three levels, corresponding, in a generic way, to the three generations of rights: on the individual level, contemplating civil and political rights; in the social, economic and social rights; and overall, collective ownership rights. We will successively focus on these different plans, considering some of the most common and impactful sanitary measures implemented in each one and which constitute human rights violations, reflecting on the possible conditions for the ethical legitimacy of the adopted measures. At the same time, it is important to consider that the sanitary measures implemented have not only negatively affected the due respect for Human Rights, but have also given rise to areas of conflict between different rights, in relation to

\footnotetext{
${ }^{1}$ Professora Catedrática de Ética, Departamento de História, Filosofia e Artes, Faculdade de Ciências Socias e Humanas, Universidade dos Açores, Ponta Delgada, Açores, Portugal. https://orcid.org/0000-0001-7246-6182. Email: m.patrao.neves@gmail.com
} 
which it is not ethically legitimate to opt for some to the detriment of others. It is argued that it is necessary to move towards a new approach to human rights, highlighting their complementarity and sustainability of duties - in an integrated model - which, in turn, should contribute to the articulation of all rights and their respective fulfillment.

\section{Keywords}

Human Rights. Duties. Freedom. Equality. Fraternity.

\section{Resumen}

La pandemia COVID-19, en la triple crisis que desencadenó - sanitaria, económica y social - ha provocado el mayor retroceso en la implementación de los Derechos Humanos desde su Declaración Universal, en 1948. Esta apreciación se deriva de su amplitud y la profundidad del retroceso en la realización de los derechos humanos que actualmente se verifica en tres niveles, correspondientes, de manera genérica, a las tres generaciones de derechos: a nivel individual, contemplando los derechos civiles y políticos; en los derechos sociales, económicos y sociales; y, en general, derechos de propiedad colectiva. Nos centraremos sucesivamente en estos diferentes planes, considerando algunas de las medidas sanitarias más comunes e impactantes implementadas en cada uno y que constituyen violaciones a los derechos humanos, reflexionando sobre las posibles condiciones para la legitimidad ética de las medidas adoptadas. Al mismo tiempo, es importante considerar que las medidas sanitarias implementadas no solo han logrado afectar negativamente el respeto a los Derechos Humanos, sino que también han dado lugar a áreas de conflicto entre diferentes derechos, en relación con los cuales no es éticamente legítimo optar por algunos en detrimento de los demás. Se argumenta que es necesario avanzar hacia un nuevo enfoque de los derechos humanos, destacando su complementariedad y sostenibilidad de deberes - en un modelo integrado - que, a su vez, debe contribuir a la articulación de todos los derechos y su respectivo cumplimiento.

\section{Palabras clave}

Derechos Humanos. Deberes. Libertad. Igualdad. Fraternidad.

\section{Nota introdutória}

A pandemia de COVID-19, ao longo de 2020 e persistindo no corrente ano de 2021, tem provocado o maior retrocesso na implementação dos Direitos Humanos de que há memória desde a sua Declaração Universal, em 1948 (1). Tal deve-se ao facto de a crise sanitária, pelas medidas de saúde pública adoptadas, ter de imediato originado uma crise económica e uma social, sem fronteiras. As três crises são hoje indissociáveis, sendo indiscutível que a crise económica e sobretudo a social persistirão para além da crise sanitária.

Neste contexto, urge identificar, de modo fundamentado e bem sistematizado, as áreas da erosão dos Direitos Humanos causada pela pandemia e explorar modalidades de intervenção que os possam vir a restabelecer e fortalecer, nas suas três gerações (2) (3) (4), como realização do maior progresso moral da humanidade na contemporaneidade. 
Começaremos por mostrar que, ao longo da história da humanidade, tem-se evidenciado e persistido um padrão no comportamento social na abordagem às doenças infectocontagiosas, que se manifesta ainda nos dias de hoje com a COVID-19. E, todavia, as circunstâncias em que esta pandemia grassa apresenta traços bastante específicos que deveriam contribuir para mitigar o impacto, amplo e profundo, que vem tendo numa pluralidade de domínios, muito em particular no cumprimento dos Direitos Humanos universalmente estabelecidos. Na realidade, as medidas sanitárias implementadas não só vêm atingindo o respeito pelos Direitos Humanos, mas têm igualmente originado áreas de conflito entre diferentes direitos, em relação aos quais não é eticamente legítimo optar por uns em detrimento de outros. Eis por que importa avançar para uma nova abordagem dos direitos humanos, destacando a sua complementaridade e sustentabilidade nos deveres num modelo integrado - o que, por sua vez, deverá contribuir para a articulação de todos os direitos e seu respectivo cumprimento.

\section{Doenças infectocontagiosas: padrão social ancestral}

A existência de doenças infectocontagiosas é ancestral (5) e as diferentes sociedades ao longo dos séculos desenvolveram mecanismos de defesa que se foram sedimentando em padrões de comportamentos em relação às mesmas que, talvez não surpreendentemente, têm genericamente persistido através de diferentes manifestações.

Recuando à Antiguidade e tomando como exemplo a Lepra (hanseníase), a doença infeciosa então de maior impacto, sabemos que os doentes, uma vez identificados, eram imediatamente expulsos e proibidos de todo o contacto com a comunidade. Na Idade Média, estes doentes deveriam usar um sino no tornozelo para anunciarem a sua passagem à distância, permitindo a todos que se afastassem. Ainda hoje a designação de leproso tem uma conotação metafórica bastante negativa classificando aquele que, saudável, é considerado de mau carácter, que não pensa no mal que causa aos outros, justificando que as pessoas se afastem dele, como malévolo. A segregação dos doentes era então a única abordagem praticada perante as doenças infecciosas numa época em que o doente era considerado impuro ou pecador, a doença um castigo divino merecido, e a sua expulsão da comunidade uma protecção necessária da sociedade que, nestas condições, não hesitava em sacrificar alguns para salvar os demais. De facto, a segregação não visa o tratamento dos doentes, mas a protecção dos saudáveis. 
Na Idade Média e Moderna, e tomando a Peste Negra como exemplo, enquanto a mais devastadora pandemia na história da humanidade, sabemos que, para além da segregação e proscrição de pessoas, se desencadearam perseguições a grupos populacionais considerados responsáveis pela disseminação da doença, com a sua consequente estigmatização. Referimo-nos a judeus, mas também muçulmanos e ciganos, além de peregrinos e estrangeiros entre outros. A estigmatização de grupos correspondia, de uma certa forma, a uma ampliação da segregação de indivíduos, devendo reverter no aumento da protecção dos demais. Ainda hoje, a interjeição metafórica comum parece que temos peste! exprime a indignação dos que se sentem injustamente excluídos. Em todo o caso, aquelas perseguições, justificadas por razões sanitárias, eram também alimentadas por objectivos económicos e políticos, sobretudo quando incidiam sobre judeus, considerados como uma ameaça para os poderes instituídos na Europa de então. A criação de bodes expiatórios era igualmente útil como estratagema para manipular o pensamento e a acção das populações amedrontadas, num aproveitamento político de um problema sanitário que se confirma intemporal.

No passado, na ausência de conhecimentos médicos e de qualquer meio de intervenção eficaz para tratamento dos doentes ou prevenção do contágio, a segregação e a estigmatização pareciam ser o único procedimento razoável perante a ameaça de contágio e morte, o que o revestimento de uma interpretação religiosa maniqueísta da doença contribuía para justificar. A estigmatização, à semelhança da segregação, não era uma acção terapêutica, mas preventiva em relação a alguns, além de que permitia também somar uma acção política despótica, servindo interesses diversos.

Na contemporaneidade, já após a evolução da arte médica para ciência experimental e da fixação de máximas do movimento dos Direitos Humanos na sua Declaração Universal em 1948, o que conjuntamente deveria prevenir as penalizadoras práticas ancestrais de protecção sanitárias, podemos tomar a SIDA (síndrome de imunodeficiência adquirida) como exemplo para evidenciarmos: quer a persistência do afastamento e isolamento dos doentes, realizado em hospitais e por parte dos profissionais de saúde, na década de 80 do século $X X$, quando esta desconhecida doença começou a surgir; quer a sua estigmatização social, na interpretação da doença como uma praga de homossexuais (gay plague), dada a sua incidência neste grupo de pessoas; quer ainda o abuso e prepotência dos poderes públicos com o encerramento de doentes em sanatórios que funcionavam como prisões, tal como aconteceu em Cuba. 
Há, pois um padrão social na abordagem às doenças infectocontagiosas que se vai repetindo ao longo do tempo e perante diferentes enfermidades, a saber: o isolamento e a exclusão de pessoas, numa acção segregadora, a diferenciação e perseguição de populações, numa acção estigmatizadora, e o abuso e prepotência de poderes, numa acção autoritária. Estas são práticas que ainda hoje violam grosseiramente os Direitos Humanos.

\section{Principais desafios que a COVID-19 coloca aos Direitos Humanos}

Este comportamento social padrão não deixou de se manifestar com a SARS-CoV-2 o que, além de nos conduzir a reconhecer que as questões humanas com que hoje nos debatemos no âmbito da COVID-19 não são verdadeiramente inéditas, também nos incumbe a urgência de delinear e implementar novas respostas no presente, isto é, medidas de intervenção nas doenças infectocontagiosas que respeitem os Direitos Humanos (6). De facto, os problemas humanos persistentes, desencadeados por epidemias e pandemias, ampliaram-se e intensificaram-se devido ao mundo globalizado em que vivemos o qual, caracterizado por uma mobilidade extrema, num espaço maximamente alargado, com escassas barreiras naturais ou humanas, facilita que a infecção pandémica progrida tão rápida quanto amplamente. Mas temos também dois factores francamente inéditos a considerar na gestão da pandemia e que, conjuntamente, devem contribuir para novas soluções humanas que de facto cuidem dos infectados e previnam o contágio dos demais. Refiro-me a factores científico-tecnológicos e sócio-políticos.

O desenvolvimento do conhecimento científico e da inovação tecnológica, para além do seu avassalador progresso num sempre crescente aceleramento em relação ao passado, é também hoje reforçado pela convergência de saberes e emergência de novas tecnologias digitais que potencializam e multiplicam os meios humanos de intervenção, bem como a sua eficácia na gestão da crise sanitária. Por isso se tem confiado na comunidade biomédica que, com recursos humanos, técnicos e financeiros ímpares, possa investir eficazmente na produção paralela de fármacos para tratamento da doença e de vacinas para a sua erradicação.

Os principais factores sociopolíticos que devem interferir positivamente na gestão da crise sanitária, mas também na económica e social, reportam-se à propagação e institucionalização de uma cultura dos direitos humanos, fortemente impulsionada pela expansão e consolidação de regimes democráticos. Este contexto exige que medidas sanitárias restritivas dos direitos humanos só possam ser implementadas, de forma 
justificada e provisória, com a anuência tácita dos cidadãos e respectivo controle sobre eventuais manifestações de abuso de poder.

Em suma, o contexto específico de uma reincidência dos ancestrais comportamentos sociais é qualitativamente diferente do apontado no passado. Tal tenderia a mitigar os impactos individuais e sociais dos comportamentos-padrão suscitados pelas doenças infectocontagiosas. E, não obstante, denunciámos já a COVID-19 como determinante da possivelmente maior regressão do movimento dos direitos humanos desde a sua origem remota no século XVII, com a afirmação de direitos naturais por John Locke. Esta avaliação decorre da amplitude e profundidade do recuo na realização dos direitos humanos (7) que se verifica actualmente em três planos, correspondendo, de uma forma genérica, às três gerações de direitos: no plano individual, contemplando os direitos civis e políticos; no social, os direitos económicos e sociais; e no global, os direitos de titularidade colectiva.

Deter-nos-emos, sucessivamente, nestes diferentes planos, considerando algumas das mais comuns e impactantes medidas sanitárias implementadas em cada um e que protagonizam comportamentos-padrão já identificados e que constituem transgressões aos direitos humanos. Será então fundamental reflectir sobre as eventuais condições de legitimação ética das medidas adoptadas.

\section{Liberdade individual}

No plano individual, temos os direitos civis e políticos, estabelecidos na Declaração Universal dos Direitos Humanos, em 1948. São direitos atribuídos a todos e a cada um dos seres humanos, estruturados a partir do valor fundamental da liberdade individual e como exigência da não interferência do Estado no que se reconhece como pertencendo ao domínio íntimo e familiar do cidadão. Neste sentido, trata-se de obrigações negativas dos Estados, isto é, de não-ingerência, uma vez que estes não são chamados a prestar qualquer bem ao cidadão, devendo restringir a sua acção exclusivamente na esfera pública, reconhecendo ao cidadão a liberdade de acção individual na sua esfera privada.

Foram precisamente os direitos civis e políticos dos cidadãos os primeiros a serem colocados em causa pelas medidas sanitárias que, visando quebrar as cadeias de contágio para contenção da pandemia, impuseram fortes restrições à mobilidade dos cidadãos, através do isolamento dos contagiados, quarentena dos respectivos contactos próximos e confinamento da população. Estas medidas determinaram diversas situações de flagrante violação das liberdades individuais em diferentes planos de intervenção. Referimos, a título 
de exemplo, o isolamento de cidadãos em quartos de hotel, durante semanas; mas também a proibição de visitas a idosos residentes em lares, durante meses; ou ainda, o estabelecimento de cercas sanitárias em zonas populacionais, por períodos mais ou menos longos - numa sequência que, constituindo uma limitação à liberdade de circulação dos cidadãos, pode ser interpretada, respectivamente, como segregação, discriminação e estigmatização.

Estas providências restritivas foram agravadas em diferentes países, através da monitorização quer do isolamento dos cidadãos (e.g. obrigados a apresentarem à polícia fotos que testemunhassem a sua presença em casa), quer da sua circulação (e.g. obrigados a medir a temperatura para acederem a alguns espaços públicos). Neste âmbito, a monitorização electrónica e a vigilância digital, com o recurso a aplicações móveis obrigatórias, algumas com geo-localização instalada, e a utilização de dados biométricos, constituem violações à privacidade dos cidadãos.

Esta sequência de restrições de direitos adquiriu algumas outras feições de índole vincadamente política a partir da declaração do estado de emergência que, a coberto da gestão da crise sanitária como sua legitimadora, permitiu a limitação do exercício da democracia (8). Em alguns casos, não raros, assistiu-se à perseguição de cidadãos e de organizações perspectivadas como inimigas do poder vigente. Referimo-nos à redução da liberdade de imprensa e à imposição do silêncio a vários profissionais, como sejam os médicos, e também à proibição da crítica ao governo ou de activismo cívico, a par da atribuição de poderes acrescidos a entidades diversas para facilitar a detenção, acusação e punição de cidadãos ou instituições que, no exercício dos direitos humanos, pudessem contrariar as normas do estado de emergência. Este é um tipo de procedimento comum em Estados autoritários, mas que também tem tido manifestações diversas em países democráticos, sobretudo a obstaculização do acesso à informação. Entretanto, a politização das medidas sanitárias adquire uma diferente expressão em governos populistas que, a coberto da defesa dos direitos humanos como justificação plausível, contrariam medidas sanitárias elementares, como se verifica sobretudo com o uso de máscaras faciais e o respeito pelo distanciamento social interpretados como assunção de uma posição política. Neste caso, são também os cidadãos, a par dos governos, que protagonizam acções atentatórias dos direitos dos humanos, expondo o conflito já antes latente entre direitos de $1^{\text {a }}$ geração, como o da liberdade, e os de $2^{a}$ geração, como o da saúde. Qualquer uma destas 
modalidades de politização da crise sanitária afecta negativamente os direitos humanos em prol do reforço de poderes políticos.

A este nível é incontestável que a liberdade é pluralmente coartada em prol da implementação de medidas de saúde pública. Coloca-se, então, de imediato, a questão acerca da admissibilidade da intervenção do Estado na restrição da liberdade individual, na sua intrusão na vida privada do cidadão (e também a consideração do que se mantém como privado, ou qual a dimensão da privacidade individual quando os níveis de interdependência social se acentuam), e na recolha e tratamento de dados pessoais, ao abrigo da situação excepcional e temporária de pandemia. No caso afirmativo impõe-se uma segunda questão acerca da fundamentação ou valores legitimadores da ingerência na esfera privada do cidadão.

Considero que a restrição da liberdade e da privacidade individuais é eticamente legítima se obedecer estritamente ao princípio da proporcionalidade na exigência de que a intervenção do Estado se limite ao mínimo necessário (na amplitude das medidas e período temporal) para alcançar os objectivos propostos, sendo que estes, por sua vez, devem ser apresentados com rigor e racionalmente justificados, reunindo o consenso da população (a forma e o conteúdo da intervenção devem estar subordinados e limitados ao fim estabelecido). O fundamento desta intervenção radica na realização do bem comum o qual, todavia, não pode ser entendido como sobreponível ao bem individual (o princípio da dignidade humana não admite que qualquer pessoa singular possa ser sacrificada a qualquer interesse social), mas antes como ele próprio indispensável para a realização do bem da pessoa, na medida em que toda a pessoa é um ser comunitário, numa rede de relações de interdependência.

Em suma, toda e qualquer restrição dos direitos humanos (civis e políticos) só será legítima se for reconhecida como indispensável, sem qualquer melhor alternativa, e eficaz para realização de fins percepcionados consensualmente como um bem maior.

\section{Igualdade social}

No plano social, temos os direitos económicos, sociais e culturais que, já enunciados nos artigos $22^{\circ}$ a $28^{\circ}$ da Declaração Universal dos Direitos Humanos, de 1948, vêm a ser desenvolvidos e reforçados no Pacto Internacional dos Direitos Económicos, Sociais e Culturais, de 1966 (9). Enquanto direitos humanos, são atribuídos a todos e cada um dos indivíduos, sendo especificamente estruturados a partir do valor fundamental da igualdade 
entre todas as pessoas e como exigência de disponibilização pelo Estado de condições materiais, quer para o real e autêntico gozo dos direitos de primeira geração, quer para a concretização da igualdade social. Neste sentido, trata-se de obrigações positivas dos Estados, isto é, do requisito de garantir a constituição de circunstâncias favoráveis e os meios necessários e satisfatórios aos cidadãos para a sua realização individual e comunitária.

Os direitos económicos e sociais foram os segundos a serem colocados em causa pelas medidas sanitárias neste tempo de pandemia. Estas, visando ainda e sempre quebrar as cadeias de contágios impuseram o confinamento geral da população e o encerramento de todas as actividades económicas não essenciais, independentemente da situação social de particular vulnerabilidade de algumas comunidades ou minorias. Tal resultou numa forte disparidade no gozo dos benefícios das medidas profiláticas, bem como no peso dos prejuízos causados pela pandemia, agravando inequidades crónicas e suscitando novas (10). Em síntese, a desigualdade económica e social e, por consequência, também a sanitária, agravou-se.

Referimos, a título de exemplo, como as mais elementares medidas profiláticas - os já apontados isolamento, quarentena, confinamento - se tornaram particularmente difíceis, senão mesmo impossíveis de cumprir por agregados familiares muito numerosos a coabitarem casas de reduzidas dimensões que obrigam à partilha constante dos espaços. Acresce que, neste contexto, há indícios significativos de que tal terá contribuído para o aumento de formas de violência doméstica e, assim também, para a deterioração da vivência social. Paralelamente, os potenciais benefícios destas medidas ficam ainda mais ameaçados se considerarmos outros factores comuns à população mais carenciada como sejam as condições de higiene de casas degradadas. A segurança e bem-estar pessoal e familiar, e sobretudo o direito à saúde, ficam, pois, seriamente comprometidos.

No domínio específico do trabalho, e sempre apenas a título ilustrativo, destacam-se duas situações diametralmente opostas e ambas fortemente penalizadoras para algumas populações mais desfavorecidas. Por um lado, a manutenção da actividade laboral pouco qualificada, mobilizando populações das periferias urbanas, obrigadas a deslocações diárias longas, em transportes públicos que tendem a rarear, sem capacidade para uma troca regular da máscara em uso o que, no seu conjunto, implica um risco acrescido de contágio. Por outro, quando se decreta a obrigatoriedade do trabalho em regime remoto, online, os meios de adaptação de que cada trabalhador dispõe são muito diversos, desde as suas 
competências digitais aos equipamentos, espaços de trabalho e acesso à internet de que dispõe. Ainda no plano do trabalho, são diversas as actividades económicas que não se podem exercer remotamente, entre as quais demasiadas que foram forçadas a encerrar, gerando falências, desemprego, dívidas e pobreza. Aliás, foram também muitos os negócios cuja actividade o Estado obrigou a suspender e muitos os funcionários obrigados a não trabalhar. O direito ao trabalho é inequivocamente negado.

Também o direito à educação se destaca como fortemente ameaçado pelas medidas sanitárias implementadas contra a COVID-19. Quando as escolas fecharam e se passou a um regime de ensino online, tornou-se evidente que nem todos os alunos dispunham de computador, câmara ou internet; nem todos tinham acompanhamento em casa, ou capacidade de concentração, ou resiliência à falta de socialização, num crescendo de inequidades de consequências ainda por calcular.

A este nível de agravamento das desigualdades sociais, como consequência directa das inevitáveis medidas governamentais no combate da pandemia, importa sublinhar que estas só serão eticamente legítimas se forem acompanhadas: primeiramente, da identificação e activação de todos os bens sociais disponíveis; e, seguidamente, do desenhar de uma estratégia da sua distribuição eficaz na promoção da igualdade entre todos os cidadãos. Ou seja, respectivamente, da plena assunção do princípio da justiça distributiva e da enunciação transparente de critérios para a sua efectiva realização. Não basta, pois, invocar o princípio da justiça, uma vez que a sua formulação consensual será sempre demasiado ampla para constituir uma normativa real: a sua definição geral ou regra de ouro de dar igual a iguais e diferente a diferentes é absolutamente formal sem especificar como se identificam os iguais e os diferentes. Além disso, existem vários modelos de justiça libertário (privilegia o interesse individual), utilitário (valoriza a máxima utilidade para a maior parte das pessoas), igualitário (estabelece uma igualdade por supressão de diferenças), comunitário (favorece o bem-comum) - a implementar de acordo com a natureza da realidade a intervir e os objectivos a alcançar. O modelo da equidade, respeita os direitos individuais (à semelhança do libertário), procura maximizar a utilidade social (à semelhança do utilitário), observa o bem comum (à semelhança do comunitário), procurando atender à especificidade das pessoas e grupos particulares para a distribuição igualitária de bens (na acepção da igualdade como equidade, ou igualdade de oportunidades). 
Em suma, toda e qualquer medida sanitária que afecte negativamente os direitos humanos (económicos e sociais) só será legítima se mantiver o compromisso real com a justiça distributiva, na promoção real da igualdade entre todas as pessoas.

\section{Fraternidade global (e o caso paradigmático das vacinas)}

No plano global, temos os direitos de titularidade colectiva ou de pertença ao género humano, direitos relativos à solidariedade global - por que mais recentemente têm sido designados - que têm vindo a ser enunciados ao longo das últimas décadas, sedimentandose em sucessivos documentos de natureza ético-jurídica (soft law), convergindo na declaração da partilha global do que é essencial para a sobrevivência e bem-estar elementar da população mundial, nomeadamente a protecção e promoção de um ambiente saudável, a preservação da identidade genética do humano, ou a paz. São direitos reconhecidos ao género humano e estruturados a partir do valor fundamental da fraternidade entre todas as pessoas e da solidariedade entre os que mais bens possuem e os que menos dispõem. Neste sentido, trata-se de obrigações positivas da comunidade internacional extensivas à população global, da inclusão desta na partilha de bens essenciais à vida digna, na participação nos benefícios da herança comum da humanidade.

Os direitos de titularidade colectiva foram os terceiros a ser colocados em causa neste tempo de pandemia vincadamente caracterizado pela carência de bens vitais para responder cabalmente às necessidades clínicas da população. Referimo-nos, sucessivamente, a material de protecção para profissionais de saúde e para a população em geral (e.g. máscaras), a equipamentos de assistência aos doentes (e.g. ventiladores), particularmente aos mais graves, a meios de testagem da população e, finalmente, às vacinas que vão sendo aprovadas. A escassez generalizada de recursos elementares para combate à pandemia conduziu a formas de actuação entre Estados de vil competição com o total desrespeito por contratos de promessa de compra e venda, ultrapassados pela oferta mais elevada numa especulação de custos que tornou os procurados bens ainda mais inacessíveis à maioria dos países. Além disso, assistiu-se, durante a primeira vaga na Europa, a actos de pirataria entre países democráticos, com o desvio de aviões de carga em trânsito ou a sua retenção e usurpação da carga em escalas técnicas.

Esta realidade altamente penalizadora para os países desenvolvidos, tornou-se ainda mais violenta para os países em vias de desenvolvimentos ou mesmo muito pobres, nomeadamente em África, contrariando o dever de partilha de bens absolutamente vitais, 
assim como a solidariedade e cooperação entre Estados. Entretanto, no que se refere aos bens de protecção e promoção da saúde que se foram tornando abundantes nos países desenvolvidos, a partilha tem-se genericamente efectuado; já em relação aos bens que permanecem escassos, como se verifica actualmente com as vacinas, é ainda a competição e o açambarcamento que imperam.

\section{O caso paradigmático das vacinas}

Neste âmbito, a problemática das vacinas merece uma atenção particular enquanto caso paradigmático da gestão dos direitos de terceira geração durante a pandemia, assistindo-se ao desenrolar de uma sequência de fases na sua evolução que suscitam diferentes apreciações éticas. Assim sendo, destacamos uma primeira marcada pelo empenho na obtenção de uma vacina eficaz contra a COVID-19, caracterizada por uma forte e muito meritória cooperação entre a maioria dos países com capacidade de investigação biomédica instalada. Estava-se então também na primeira vaga da pandemia e vivia-se uma impotência generalizada face à dimensão da ameaça: importava reunir esforços, a nível mundial, para desenvolver uma vacina que pudesse libertar a humanidade do flagelo da pandemia.

À medida, porém, que a investigação progredia e iam surgindo resultados preliminares animadores, a cooperação foi cedendo à competição. Eis o que se tornou evidente quando, já no Verão de 2020, as empresas farmacêuticas e de biotecnologia começaram a disputar pequenos e grandes sinais do respectivo sucesso que iam alcançando: resultados da $3^{a}$ fase dos ensaios clínicos, datas de conclusão da investigação, percentagens de eficácia alcançada - sempre com um notório impacto bolsista.

Foi já neste clima de intensificação da concorrência e rivalidade que os países mais ricos se lançaram numa corrida às vacinas cuja respectiva aprovação pelas entidades competentes se ia anunciando. Os preços aumentaram então, natural e simultaneamente à medida que também a previsível escassez de vacinas face às necessidades se ia tornando mais manifesta. Este último aspecto encorajou a negociações bilaterais o que, previsivelmente, reforçou a posição da indústria farmacêutica com repercussão nos preços de venda. A competição aberta permitiu que alguns países tivessem adquirido um volume de vacinas superior às suas necessidades e marginalizou ainda mais alguns outros do acesso a que também aspiravam. Actualmente, a já certeza de necessidade de reforço da vacinação com uma terceira dose a partir do Outono de 2021 (mesmo que apenas para 
alguns grupos como imunodeprimidos ou idosos em geral) amplia o volume de aquisições por parte dos países desenvolvidos, aumenta mais uma vez o preço das vacinas e aprofunda a sua inacessibilidade por parte dos países mais pobres. Esta é uma realidade pungente que penaliza muitos e não salvaguarda absolutamente ninguém: a pandemia é, por definição, global e só globalmente pode ser debelada, sendo que os espaços, as populações a que as vacinas não chegam se podem converter em laboratórios naturais de novas variantes com efeitos imprevisíveis na saúde global.

Neste contexto dramático que há mais de um ano se vem desenhando, surgiu, em Outubro de 2020, uma proposta de suspensão de patentes liderada pela África do Sul e Índia, no âmbito da Organização Mundial do Comércio (OMC). Esta hipótese foi-se expandindo e reforçando a sua credibilidade, recebendo apoios significativos de instituições como a UNESCO, o Alto-comissário das Nações Unidas para os Direitos Humanos (ACDH) e a própria Organização Mundial de Saúde (OMS) (11). A vacina é considerada um bem público global, isto é, uma realidade reconhecidamente benéfica e essencial para o bemestar da humanidade que, como tal, Ihe pertence, não devendo ficar cativa de ninguém, à semelhança de qualquer outra propriedade privada (12). A proposta, aparentemente tão simples quanto eficaz, foi, não obstante, igualmente interpretada como podendo ser ainda mais penalizadora do que a situação actual para os países à margem do circuito das vacinas. Com efeito, a suspensão das patentes das vacinas, além de muito difícil se não mesmo impossível devido ao elevado número de empresas implicadas na produção de cada uma das suas componentes, desincentivaria também as farmacêuticas de produzirem (para além dos impactos futuros ao nível da investigação científica) as vacinas já aprovadas para a COVD-19, ficando este encargo para os diferentes países de acordo com as suas necessidades. Para além do risco em termos de qualidade e segurança, poucos seriam os países do mundo com esta capacidade adquirida. Assim sendo, os países actualmente sem acesso às vacinas, cuja distribuição aguardam por parte das farmacêuticas, continuariam a aguardar a sua distribuição, desta feita por parte de outros países cujo preço de venda não seria apenas monetário mas também de influência, entre outras possíveis compensações. Se não existir um real benefício sustentável, então a iniciativa desencadeada por países que teriam possibilidade de a produzir para si e para outros pode ser perspectivada como mais um negócio rentável sob o discurso da urgência de partilha.

Também o caso da iniciativa tardia dos Estados Unidos, em Maio de 2021, de apoiar a suspensão das patentes, seguida de uma posição inicialmente dúbia da União Europeia 
pode ser facilmente ser interpretada como estratégia de conquista de influência política. À data, os Estados Unidos não tinham oferecido uma única vacina a países pobres, tendo já garantido todas as vacinas necessárias para a sua população; em contrapartida, a União Europeia havia autorizado a exportação de metade da sua produção de vacinas e começado a doar também, apesar de ainda não ter garantido a aquisição de todas as doses necessárias para os europeus. No decurso deste debate, a União Europeia, no respeito pelas patentes, mas também no imperativo de aumentar a produção de vacinas, propôs o que pode ser considerado como uma via intermédia e conciliatória de todos os interesses em causa, a de adopção do licenciamento compulsório ao abrigo do qual o titular da patente é remunerado pela partilha de conhecimentos e técnicas. Esta medida seria complementar à do reforço do projecto de Acesso Global às Vacinas da Covid-19 (COVAX) (13). Esta é uma iniciativa das Nações Unidas que, através da angariação de fundos internacionais procura tornar as vacinas acessíveis a preços reduzidos para países pobres, inoculando cerca de $20 \%$ da população de países em vias de desenvolvimento, assim contribuindo para um acesso equitativo e universal a vacinas, numa abordagem internacional, mundial, inclusiva. A COVAX, estando já operacional, se bem que a um nível de desempenho ainda claramente insuficiente que carece de forte investimento, constituirá a resposta mais eficaz à escassez e mesmo ausência de vacinas para algumas populações em diversas regiões do nosso mundo.

As variáveis que influenciam esta discussão acerca das patentes são muito numerosas, o mesmo se verificando com as dinâmicas das suas interrelações, pelo que o debate se mantém necessariamente em aberto e sob escrutínio a coerência entre o que as palavras anunciam e o que as acções concretizam.

A este nível, a exclusão liminar de países e populações dos meios essenciais e indispensáveis para combater a pandemia não encontra cobertura ética, quando reconhecermos a dignidade da pessoa como valor absoluto e, por isso, igual de todas as pessoas. Não só sob uma perspectiva ética, mas também clínica, a exclusão de populações da vacinação constituirá sempre um fracasso no combate da pandemia, o qual exige uma abordagem global - tal como já destacámos - sem a qual o risco de contágio e infecção persistirá. Dada a desigualdade entre os vários países do mundo, só através da cooperação e da solidariedade dos mais afortunados em relação aos mais carenciados se poderá minorar as necessidades vitais e contribuir para uma equidade global. Verifica-se facilmente que, no que se refere aos bens abundantes nos países desenvolvidos, a partilha tem-se 
genericamente efectuado; já em relação aos bens escassos, como são actualmente as vacinas, é a lógica da competição que persiste. O caso das vacinas é paradigmático de uma solidariedade estreita, de uma partilha restrita ao que sobra a quem dá e não cobrindo as necessidades de quem carece- numa prática acanhada dos valores que assistem ao reconhecimento dos direitos à humanidade, como um todo.

Em suma, o respeito, eticamente exigido, pelos direitos colectivos, da comunidade humana, poderá e deverá ser voluntária e solidariamente promovido, mas terá de ser obrigatoriamente cumprido, do ponto de vista sanitário, para terminar a pandemia.

\section{Articulação dos direitos da pessoa, da comunidade e da humanidade}

A emergência de epidemias, ao longo da história da humanidade, implicou sempre o sacrifício dos interesses e bem-estar de alguns em prol dos da maioria. E, todavia, a doutrina dos direitos humanos, fixada na sua Declaração Universal, obrigou-nos a ultrapassar a mera contabilidade dos números, no reconhecimento de que cada pessoa é um absoluto singular, único e insubstituível, que não pode ser reduzida à homogeneidade neutra de algarismos. Ou seja, os direitos da pessoa e os direitos da comunidade não se apresentam como alternativas perante as quais a opção por uma determina a supressão da outra. Antes se impõem hoje como obrigações a respeitar conjuntamente. Neste sentido, exigem articulação adoptando uma lógica de inclusão, e não de selecção seguindo uma lógica de exclusão.

No caso da pandemia que se vive, a exigência ultrapassa todas as fronteiras e estende-se à humanidade na sua totalidade, ou seja, obriga à articulação dos direitos das pessoas, dos direitos das comunidades e dos direitos da humanidade. Ora, é precisamente a estes três níveis que os Direitos Humanos estão a sofrer um retrocesso ímpar na história da sua implementação a que não podemos somar o conflito entre os três. Pelo contrário, é no empenho na sua recíproca harmonização que podemos mitigar os impactos nefastos de cada um dos três níveis.

Assim, diria que, ao nível dos direitos individuais, civis e políticos, seria desejável equilibrar o princípio da autonomia individual - como poder de tomar decisões acerca do que a si lhe diz respeito - com a o da responsabilidade social - como obrigatoriedade de responder positivamente às necessidades no outro, na medida do seu poder -, o que conduziria à abdicação voluntária, parcial e provisória da liberdade e da privacidade na justa percepção que também o interesse privado à saúde apenas se realiza, numa situação de 
pandemia, quando se promove a saúde pública. Assim o repto é que cada cidadão se torne num agente de saúde pública.

Ao nível dos direitos sociais, económicos e sociais, seria desejável majorar o princípio da justiça distributiva com uma atenção acrescida ou cuidado maior pelos mais vulneráveis (o princípio da vulnerabilidade exige uma protecção especial proporcional às vulnerabilidades, ou exposição a ser ferido, atingido, à ofensa) na certeza de que o bem dos mais carenciados se repercute em toda a sociedade, beneficiando-a. O bem de cada um contribui para o bem comum, o que exige o descentramento em si, numa postura individualista, e a abertura ao outro, numa postura altruísta, na construção de uma comunidade, na partilha de vida dos seus cidadãos.

Ao nível dos direitos de titularidade colectiva mantém-se a lógica de que o melhor para os que estão em piores condições beneficia também os que já estão melhores, a par da exigência fundamental (prima facie) de garantir condições mínimas e suficientes de vida digna a todos os seres humanos. A cooperação e a solidariedade são, de facto, o único caminho eficaz para todos, a partir do reconhecimento da interdependência global em que cada um e todos nós vivemos. O bem comum contribui para o bem de cada um e a protecção do bem individual é uma obrigação ética de todos.

Em suma, a melhor estratégia para garantir os direitos a todos é o cumprimento do dever de cada um.

\section{Referências}

1. Nações Unidas. Declaração Universal dos Direitos Humanos. Disponível em: https://unric.org/pt/declaracao-universal-dos-direitos-humanos/

2. Vašák K. Human Rights: A Thirty-Year Struggle: the Sustained Efforts to give Force of law to the Universal Declaration of Human Rights. UNESCO Courier. 1977;(11):29-32

3. Bobbio Norberto. L'età dei diritti. Giulio Einaudi Editore; 1990.

4. Council of Europe. The evolution of Human Rights. Disponível em: https://www.coe.int/en/web/compass/the-evolution-of-human-rights

5. Nogueira Pinto J. Contágios. Lisboa: Publicações Dom Quixote; 2020.

6. Gaudêncio AM. Direitos Humanos e Pandemia. In: Dias Pereira A (coord.). Responsabilidade em Saúde Pública no mundo Lusófono. Fazendo Justiça durante e além da emergência da COVID. Coimbra: Instituto Jurídico, Faculdade de Direito da Universidade de Coimbra; 2021. 11-23 p. 
7. Kjaerum M, Davis MF, Lyons A. COVID-19 and Human Rights. Routledge; 2021.

8. Council of Europe. Respecting democracy, rule of law and human rights in the framework of the COVID-19 sanitary crisis: A toolkit for member states. 7 de Abril de 2020. Disponível em: https://rm.coe.int/sg-inf-2020-11-respecting-democracy-rule-of-law-and-human-rightsin-th/16809e1f40

9. Nações Unidas. Pacto Internacional dos Direitos Económicos, Sociais e Culturais. Disponível

em:http://www.dge.mec.pt/sites/default/files/ECidadania/educacao para a Defesa a Seg uranca e a Paz/documentos/pacto internacional sobre direitos economicos sociais cul turais.pdf

10. United Nations. Human rights are critical - for the response and the recovery. 2020. Disponível em:

https://www.un.org/victimsofterrorism/sites/www.un.org.victimsofterrorism/files/un human rights and covid april 2020.pdf

11. UNESCO. UNESCO, WHO and the UN High Commissioner for Human Rights call for "open science". 27 de Outubro de 2020. Disponível em:

https://en.unesco.org/news/unesco-who-and-high-commissioner-human-rights-call-openscience

12. UNESCO. UNESCO calls for COVID-19 vaccines to be considered a global public good. 24 de Fevereiro de 2021. Disponível em:https://en.unesco.org/news/unesco-callscovid-19-vaccines-be-considered-global-public-good

13. WHO. The Access to COVID-19 Tools (ACT) Accelerator. Disponível em: https://www.who.int/initiatives/act-accelerator

Patrão Neves M. Os desafios da COVID-19 aos Direitos Humanos. Cadernos Ibero-Americanos de Direito Sanitário. 2021 jul./set.;10(3):66-82.

https://doi.org/10.17566/ciads.v10i3.825 